Abstracta Iranicacta Iranica

Revue bibliographique pour le domaine irano-aryen

Volume 34-35-36 | 2017

Comptes rendus des publications de 2011-2013

\title{
Barbara Karl. Treasury, Kunstkammer, Museum: Objects from the Islamic World in the Museum Collections of Vienna
}

Viola Allegranzi

\section{(2) OpenEdition \\ 12 Journals}

Édition électronique

URL : http://journals.openedition.org/abstractairanica/41877

DOI : 10.4000/abstractairanica.41877

ISSN : 1961-960X

Éditeur :

CNRS (UMR 7528 Mondes iraniens et indiens), Éditions de l'IFRI

Référence électronique

Viola Allegranzi, «Barbara Karl. Treasury, Kunstkammer, Museum: Objects from the Islamic World in the Museum Collections of Vienna », Abstracta Iranica [En ligne], Volume 34-35-36 | 2017, document 13, mis en ligne le 30 décembre 2016, consulté le 26 septembre 2020. URL : http://journals.openedition.org/ abstractairanica/41877 ; DOI : https://doi.org/10.4000/abstractairanica.41877

Ce document a été généré automatiquement le 26 septembre 2020

Tous droits réservés 


\title{
Barbara Karl. Treasury, Kunstkammer, Museum: Objects from the Islamic World in the Museum Collections of Vienna
}

\author{
Viola Allegranzi
}

\section{RÉFÉRENCE}

Barbara Karl. Treasury, Kunstkammer, Museum: Objects from the Islamic World in the Museum Collections of Vienna. Vienne, Verlag der Österreichischen Akademie der Wissenschaften, 2011, 139 p., 82 ill. couleur. (Veröffentlichungen zur Iranistik, 62. Band/SBph, 822.

Band)

1 Cet ouvrage est issue d'un projet de recherche conduit entre 2008 et 2010 par Barbara Karl, conservatrice des textiles et tapis au musée d'arts appliqués de Vienne (le MAK), sous la tutelle de l'Institut d'études iraniennes de l'Académie autrichienne des sciences. Son objectif est d'offrir un panorama général des objets islamiques dispersés dans les musées, cabinets et bibliothèques de Vienne, qui sont dépositaires des anciennes collections impériales des Habsbourg. En raison de la quantité d'objets (environ 40000 pièces au total) et de leur diversité, le format retenu n'est pas celui d'un catalogue raisonné. L'A. choisit plutôt de donner une reconstitution méticuleuse de l'histoire des collections, en mettant en avant les ensembles les plus méconnus.

Une première section passe en revue les différentes phases de la constitution des collections des Habsbourg, du XIV ${ }^{\mathrm{e}}$ au XIX ${ }^{\mathrm{e}}$ s., et illustre les modalités d'acquisition des objets islamiques : trésors rapportés des croisades et remployés comme reliquaires ou mobiliers, mais aussi regalia et butins de guerre qui témoignent des rapports du SaintEmpire romain germanique avec les grandes dynasties de l'Orient, en particulier, les Ottomans, les Safavides et les Moghols. Une deuxième section est consacrée aux 14 
institutions viennoises qui abritent des objets islamiques : la nature hétérogène des collections ressort de cette "promenade ", en incluant tant des objets de formes et fonctions variées, en céramique, métal, verre et bois, que des armes, des textiles, des monnaies, des manuscrits, des instruments scientifiques et musicaux, etc. Plusieurs groupes d'objets de nature, datation et provenances diverses sont rapidement évoqués, avec des références ponctuelles aux numéros d'inventaires, notices de catalogues et études existantes.

3 Sur l'ensemble des collections, l'art ottoman constitue le principal noyau, pour des raisons géographiques et historiques évidentes. Mais les productions iraniennes sont bien représentées à travers les époques : mentionnons, parmi d'autres matériaux, la vaisselle en céramique, en métal et en verre (IX ${ }^{\mathrm{e}}$-XIII $\left.{ }^{\mathrm{e}} \mathrm{s} ., \mathrm{MAK}\right)$; les nombreux textiles, parmi lesquels un lampas en soie ilkhanide (XIV ${ }^{e}$ s., Dommuseum) ; les coupes et la jarre timourides en néphrite $\left(\mathrm{XV}^{\mathrm{e}} \mathrm{s}\right.$., KHM) ; les sabres safavides $\left(\mathrm{XVI}^{\mathrm{e}}-\mathrm{XVII}^{\mathrm{e}} \mathrm{s}\right.$., Deutsche Orden) ; les médaillons et portraits des shâhs qâjârs (XIX' s., Münzkabinett et Belvedere).

4 Bien que le petit format des 82 illustrations ne permet pas un aperçu exhaustif des collections d'art islamique à Vienne, le travail de Karl atteint son objectif : attirer l'attention sur un patrimoine artistique riche et diversifié qui nécessite encore à présent d'être dûment valorisé et étudié.

\section{AUTEURS}

VIOLA ALLEGRANZI

Université Sorbonne Nouvelle - Paris 3 et Università degli studi di Napoli « L'Orientale » 